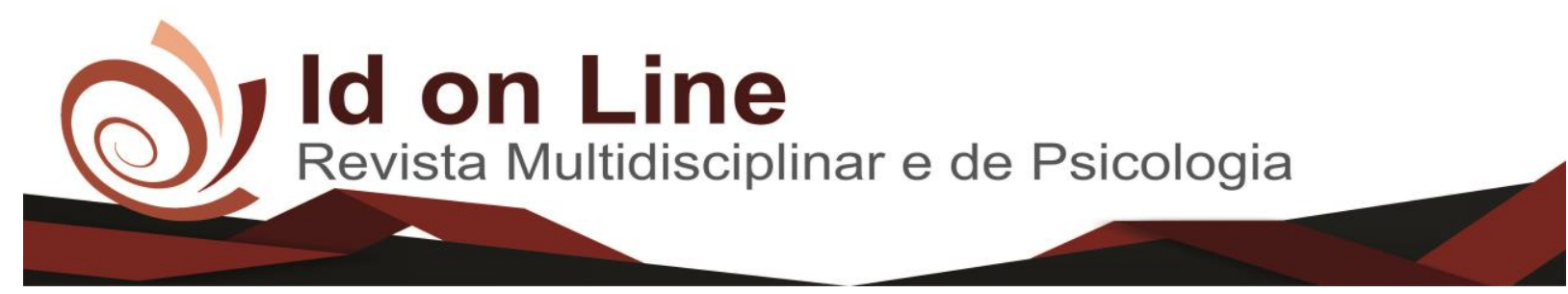

Estudo de Caso

\title{
Avaliação da Qualidade de Vida no Trabalho: Estudo de Caso em duas Escolas Particulares no Cariri Cearense
}

\author{
Marysângela de Oliveira Tavares ${ }^{l}$; Islly Gabrielle Tavares Limachi ${ }^{2}$
}

Resumo: A qualidade de vida no trabalho (QVT) vem ganhando espaço como valor essencial das práticas que visam o bem-estar organizacional. Neste contexto, é preciso desenvolver estratégias e habilidades que visem uma maior produtividade, visando um posicionamento mais competitivo no mercado. O presente estudo buscou analisar a qualidade de vida no trabalho, em duas escolas na região do cariri cearense. Optou-se pelo estudo de caso nestas instituições, de forma a observar a percepção dos professores quanto a sua qualidade de vida no trabalho. Os resultados demonstraram uma superioridade nas medias referentes aos critérios de integração social na organização e relevância social do trabalho na vida, levando acrer que não há discriminação das instituições junto aos funcionários e que as escolas pesquisadas gozam de boa imagem no que se refere ao relacionamento com a comunidade.

Palavras-chave :, Comportamento Organizacional, Comunicação, Cultura, Clima, Qualidade de vida

\section{Quality of Life Assessment at Work: A Case Study in two private schools in Cariri, Ceará}

\begin{abstract}
Quality of life at work (QWL) has been gaining ground as an essential value of practices that aim at organizational well-being. In this context, it is necessary to develop strategies and skills that aim at greater productivity, aiming at a more competitive position in the market. The present study sought to analyze the quality of life at work in two schools in the Cariri region of Ceará. We chose a case study in these institutions, in order to observe the teachers' perception of their quality of life at work. The results showed a superiority in the means related to the social integration criteria in the organization and social relevance of the work in the life, implying that there is no discrimination of the institutions with the employees and that the schools studied have a good image with regard to the relationship with the community.
\end{abstract}

Keywords: Organizational Behavior, Communication, Culture, Climate, Quality of Life

\section{Introdução}

Em pleno século XXI são discutidos assuntos fundamentais na vida do ser humano, que já podiam ter sido evitados e resolvidos nos séculos anteriores. Quando o assunto é Qualidade de Vida no Trabalho (QVT), alguns dos empregadores não demonstram a devida importância para o tema.

\footnotetext{
${ }^{1}$ Graduação em Administração pela Faculdade Paraíso do Ceará (2011), graduação em Geografia pela Faculdade de Formação de Professores de Serra Talhada e Especialização em Geografia e Meio Am pela Universidade Regional do Cariri. Contato: tavaresmarysangela@gmail.com;

${ }^{2}$ Graduação em Administração pela Faculdade Paraíso do Ceará (2011). Atualmente é professora de administração da Faculdade Latino Americana de Educação . Contato: nenita2011@ hotmail.com;
} 
Contudo, é sabido que quando existe uma preocupação com a Qualidade de Vida no Trabalho (QVT), se mitigam possíveis transtornos como: stress, elevados índices de absenteísmo, baixa produtividade, não cumprimentos de prazos e metas e comprometimento da motivação, o que provoca um baixo desempenho na organização.

Os empregadores têm a concepção de que a implementação de ações para melhoria da Qualidade de Vida no Trabalho (QVT) acarreta em custo elevado e desnecessário, e não percebem este desafio como um investimento com retorno satisfatório para a organização. Os empregados precisam ser reconhecidos para sentirem-se melhores, e para isto acontecer as organizações têm que abraçar melhor a idéia de integração, onde os padrões organizacionais não dependem somente de critérios técnicos, mas também dos sistemas sociais trabalhando juntamente com as áreas afins, como:saúde, segurança, benefícios, gestão, certificação de qualidade, comunicação interna, e a área de Recursos Humanos que enriqueceria a vida laboral destes.

Os colaboradores buscam cada vez mais crescer na organização, gostariam de ter mais oportunidades e entendem que os critérios técnicos não podem ir só, tanto por que as organizações estão conformadas por pessoas e estas buscam realizar tanto a aérea técnica quanto a aérea social; buscando cada vez mais a auto-realização, crescimento Professional, entre outros.

Devido a estas inquietudes algumas empresas estão implementando a QVT com o objetivo de adquirir conhecimentos, aspirações, aptidões e motivação também, desenvolvimento das próprias capacidades, vida e trabalho dignos, participação democrática, e o próprio melhoramento da qualidade de vida.

A QVT vem ganhando espaço como valor essencial das praticas de competitividade constantemente ao bem-estar organizacional enfocando o contexto, onde as organizações procuram a produtividade e processos de mudança onde para ter posicionamento competitivo no mercado precisa-se melhorar seu posicionamento.

Para a realização da pesquisa formulou-se o seguinte problema: Qual a percepção dos colaboradores das escolas selecionadas sobre a qualidade de vida no trabalho (QVT), experimentada nestas?

Desta forma, para atingir o tema, foco e escopo da pesquisa foi necessário a formulação do seguinte objetivo geral: Analisar a qualidade de vida no trabalho dos 
colaboradores das escolas selecionadas. Para atingir o objetivo geral foram estabelecidos os seguintes objetivos específicos: 1. Identificar os fatores de avaliação de qualidade de vida no trabalho; 2. Identificar os fatores de qualidade de vida no trabalho com melhor avaliação na percepção dos colaboradores das escolas; 3. Identificar os fatores de qualidade de vida no trabalho percebidos como deficientes pelos colaboradores das escolas em estudo.

Pode-se observar que existe uma variada e ampla fonte literária que nos insere ao tema QVT, seus conceitos, campos de atuação na esfera privada. Tornando-se de primordial relevância uma reflexão mais critica e profunda acerca do tema proposto haja visto a estabilidade do setor privado, hipótese levantada haja vista a crescer a desmotivação pela excelência do serviço privado gerada por esta estabilidade que permite aos colaboradores de agir desta forma e/ou a não remuneração justa exercida pelo Professional.

Analisar o nível de qualidade de vida no trabalho dos funcionários educacionais tornase de primordial importância no sentido de que será uma nova partida para construir uma nova qualidade de vida no trabalho voltada ao serviço privado.

\section{Comportamento Organizacionais}

O reconhecimento do comportamento organizacional com elemento intrínseco a gestão começou na década de sessenta por pesquisadores ingleses. O comportamento organizacional (CO), enquanto campo de conhecimento dedica-se a estudar o capital humano, abarcando a gestão de pessoas ou administração de recursos humanos (ARH); focalizando o comportamento individual e grupal nas organizações. Segundo (CHIAVENATO, 2005).

Durante este período o assunto Obteve as mais variadas e diferentes conceituações, e após quatro décadas, o $\mathrm{CO}$ adquiriu solidez e passou a ser utilizado como referencial em proposições teóricas, e surgissem pesquisas empíricas relacionadas ao tema. (Siquiera et al, 2006)

As primeiras tentativas para delimitar o campo do CO surgiram na década de 60, quando Pugh $(1966 ; 1969)$ observou que outras disciplinas das aéreas humanas (sociologia, psicologia) mantinham a idéia de independência do $\mathrm{CO}$, já que na organização estão inseridos 
vários tipos de comportamentos, grupais, indivíduais e diferentes maneiras de funcionamentos, tornando-a uma ciência emergente.

"Em 1984 surgiu uma intervenção realizada por Staw (1984), na qual o CO foi definido como". "Um campo multidisciplinar que examina o comportamento de indivíduos dentro de ambientes organizacionais, como também a estrutura e o comportamento das próprias organizações" (p. 628). Para este autor o individuo é analisado dentro dos diferentes ambientes da organização para assim ter uma compressão especifica do comportamento deste.

Atualmente, ainda persistem divergências quanto à conceituação do CO. Outras definições foram publicadas, por exemplo, para (ANDREW 2008) o Comportamento Organizacional é um estudo que trata de aclarar, prevenir e controlar os desempenhos da organização como um todo; por outro lado, para ROBBINS (2005) o CO enfatiza que se precisa investigar o indivíduo, inserido em grupos, e a composição que estes têm dentro das organizações, para auxiliar na melhoria da eficácia organizacional, colocando o individuam como peça fundamental neste estudo.

De acordo com Chiavenato (2005) o comportamento organizacional (CO) estuda os indivíduos atuando nas organizações e as influências que estes sofrem e, vice-versa, obtendose, aprendizados recíprocos e continua interação entre pessoas e organizações.

O mesmo autor (CHIAVENATO 2007, p.140) complementa:

Que por mais que desejemos olhar para as pessoas como recursos de lucratividade não deveriam esquecer que pessoas são pessoas, e que são portadoras de particularidades e características próprias; tendo sonhos, expectativas, e objetivos pessoais que almejam alcançar, etc.

Sempre que na discussão estiverem pessoas, surgem milhares de itens para serem abordados de perspectivas diferentes, já que o ser humano é único e incomparável levando consigo ações, medos, realizações, percepções, aprendizado, atitudes, motivações, etc. Quando este ser humano está inserido numa organização, os impactos que influenciam este são mais abrangentes como: normas, papéis, equipes, cultura, clima e conflitos; e muitas vezes podem ocasionar a destruição do mesmo.

Argüi Robbins (2005), que a ciência antropológica faz uma contribuição quando incorpora ao individuo temas como: valores, atitudes, cultura, ambiente organizacional e multicultural, estando inserido. O individuo traz consigo como: medos, valores, atitudes, 
ambiente, cultura, motivação, entre outros; tudo isto é perceptível quando ele é inserido no médio.

\section{Comunicação, Cultura, Clima organizacional}

Desde que nasce o ser humano, este sempre esta se comunicando; informa sua cultura pela roupa que veste no meio laboral, sua forma de tomar decisões, de encarar as preções laborais, demonstra suas atitudes, sua coragem. Esta a todo o momento se comunicando, desde o olhar até, o gesto, além de outros elementos, ele desvenda seus valores. É pela análise da comunicação de uma empresa que percebemos o pensar e o sentir dos indivíduos dentro da organização.

Alguns autores definem a comunicação como: um procedimento de intercambiar dados com outras pessoas; podendo ser um pensamento, acontecimento, notícia ou mesmo uma idéia que um individuo queira compartilhar com outras. (CHIAVENATO 2005) “A comunicação constitui a primeira aérea a ser focalizada quando se estuda as interações humanas e os métodos para mudança ou influencia (persuasão) do comportamento humano nas organizações." (CHIAVENATO, 2005, pg314).

A comunicação em algumas ocasiões poderá auxiliar ao indivíduo para obter melhorias na sua própria eficácia e no seu relacionamento interpessoal. Segundo Chiavenato, (2005), que define a Comunicação Organizacional como: o processo restrito de dados intercambiamos em uma determinada organização, estabelecendo um entendimento comum sobre o assunto a ser abordado.

Existem alguns assuntos que são tratados em lugares específicos, com pessoas especificas, não podendo ser transmitidos em outros ambientes. Toda organização tem a sua cultura própria. A cultura organizacional repousa sobre um sistema de crenças e valores, tradições e hábitos, uma forma aceita e estável de interações e de relacionamentos sociais típicos de cada organização. Algumas organizações conseguem renovar constantemente sua cultura mantendo a sua integridade e personalidade, enquanto outras permanecem com sua cultura amarrada a padrões antigos e ultrapassada.

Cultura, segundo o Dicionário Aurélio é: 
O complexo dos padrões de comportamento, das crenças, das instituições e de outros valores espirituais e materiais transmitidos coletivamente e característicos de uma sociedade; civilização" (Dicionario Aurelio).

Então, quando nos referimos à Cultura Organizacional estamos enfocando padrões de comportamento, crenças e valores espirituais e materiais de uma organização.

Schein (apud Freitas, 1991, p.7) denota a cultura organizacional como:

O modelo dos pressupostos básicos, que determinado grupo tem inventado, descoberto ou desenvolvido no processo de aprendizagem para lidar com os problemas de adaptação externa e integração interna, uma vez que os pressupostos tenham funcionado bem o suficiente para serem considerados válidos, são ensinados aos demais como a maneira correta para se perceber, se pensar e sentir-se em relação aqueles problemas.

$\mathrm{O}$ autor preocupa-se em ir além do comportamento observado; enfocando os pressupostos que descrevem o sentir e o pensar dos indivíduos de um determinado grupo.

Segundo Oliveira, a cultura empresarial é denominado como o "Conjunto de valores e crenças vigentes na organização e aos comportamentos individuais e coletivos decorrentes" (1988, p.34) Para Oliveira (1988) a cultura não se pode mudar da noite para a manhã, ela requer um processo de mudança. Esta afirmação esta fundamentada no que muitos consultores e administradores defendem, a idéia de que não se pode alterar a cultura de uma organização simplesmente como uma troca de peças por outras melhores.

De alguma maneira $\mathrm{O}$ clima organizacional é o resultado da cultura na organização, ou talvez seja o reflexo dos resultados dessa cultura abarcando aspectos negativos (conflitos) e positivos. (Taniguchi et al ,2009). Portanto, para Luz (2005) e Soares (2002) o clima organizacional é resumido pelo comportamento interno que pode variar segundo a motivação, satisfação e insatisfação dos indivíduos na organização.

Clima organizacional é o tempo para definir o conjunto de satisfações e insatisfações dos membros de uma organização em um determinado período, geralmente identificado através de pesquisas calcadas em percepção e opinião. É mais volátil e menos estrutural que a cultura organizacional. (FREURY \& SAMPAIO, 2002, P.293).

O Clima é o ambiente mensurável no qual estamos inseridos no dia a dia, este médio pode influenciar a motivação e o comportamento das pessoas; sendo também um indicador de satisfação, onde a cultura tem um papel fundamental podendo influenciar integrantes de uma 
empresa diretamente na produtividade. "O clima organizacional não deve ser apenas gerenciado, mas também, constantemente analisado. "' (LUZ, 2003, P.42)

É fundamental que as organizações acompanhem o grau de satisfação e insatisfação dos seus colaboradores, e possam identificar seus valores, sua missão e futuro almejado, e isto retornasse como uma estratégia direcionada para o aperfeiçoamento contínuo e para a mudança. Segundo Shibutani apud Edela (1978):

\begin{abstract}
Cada pessoa aborda o mundo do ponto de vista da cultura do seu grupo, cada um percebe, pensa, forma julgamentos e controla a si mesmo de acordo com o quadro de referencia do grupo do qual participa. Como ele define objetos, outras pessoas, o mundo e a si próprio a partir da perspectiva que compartilha com outros, ele pode visualizar sua linha de ação proposta a partir desse ponto de vista generalizado, antecipar a reação dos outros, inibir impulsos indesejáveis e assim dirigir sua conduta.
\end{abstract}

Em certos casos se devem criar canais onde os conflitos sejam trazidos e discutidos de forma natural, tendo à oportunidade a solução prévia dos problemas colocados, e assim levando isto a uma mudança no clima organizacional

\title{
Individuo na Organização
}

O termo individuo (Ferreira, 1986, p.70), quando substantivo, refere-se a "pessoa humana, considerada quando as suas características particulares, físicas e psíquicas”. Uma organização é formada de pessoas, que tem necessidades, interesses, sonhos, potencialidades, medos e limitações.

Segundo Piéron (1964), a individualidade das pessoas se complementa quando elas se misturam com as demais pessoas. Desta maneira o convívio no dia a dia nos grupos sociais (nos quais se incluem os grupos de trabalho) possibilita a expansão e o desenvolvimento dos indivíduos.

No cenário atual, a variabilidade de recursos escassos a serem otimizados são muitos, devido a este impasse o trabalho em equipe aparece como alternativa fundamental na gestão de recursos para levar a organização a patamares de desempenhos desejados. 


\section{Qualidade de vida no Trabalho}

O tema qualidade de vida tem sido objeto de reflexão desde tempos remotos; devido a busca de melhores condições de vida, estas condições são obtidas no trabalho. Segundo BomSucesso (1987, p. 7) o significado da palavra trabalho é:

\footnotetext{
A palavra trabalho, do latim tripalium, refere-se a instrumento de tortura utilizado para punir criminosos que, ao perderem a liberdade, eram submetidos a trabalho forçado. Nesta origem, o trabalho era concebido como algo humilhante $\mathrm{e}$ desqualificante.
}

Abordar o assunto QVT é muito extenso, já que compreende de um lado a aquisição de conhecimentos, aspirações, aptidões e motivação e por outro, desenvolvimento das próprias capacidades, vida e trabalho dignos, participação democrática, e o próprio melhoramento da qualidade de vida.(Chiavenato 1999)

É fundamental reconhecer o trabalho como experiências de convivências saudáveis, de respeito e comprometimento na contribuição da QVT. Devido ao fato do trabalho ocupar um tempo significativo no nosso dia a dia, formando um laço de relação entre o empregado e o empregador.

Na década dos 40 e 50, movida pela necessidade de se contrapor a desumanização no trabalho, , surge a Teoria das Relações Humanas, com a concepção de homem social, que precisa interagir, trocar idéias, mostrar seus sentimentos, desejos e temores, considerando-o um ser complexo e único. Alguns indivíduos, precisam de certos grupos para alcançar suas metas e poder suprir suas necessidades e satisfações, interagindo constantemente com estes. (QUEIROZ, 1996, apud CHIAVENATO, 1983)

Segundo o Grupo WHOQOL (1998), a expressão qualidade de vida foi empregada pela primeira vez pelo presidente dos Estados Unidos, Lyndon Johnson, em 1964, ao declarar que "os objetivos não podem ser medidos através do balanço dos bancos. Eles só podem ser medidos através da qualidade de vida que proporcionam às pessoas".

Atualmente, fala-se em qualidade de vida com muita frequência, tendo em vista a expectativa de vida mais longa, o que traz à tona questões relacionadas ao aumento do número de anos vividos, mas também e principalmente, a qualidade de vida neste período, 
como já foi dito anteriormente. Este termo tem provocado diversas reflexões e tem sido objeto de muitos debates. Estudiosos no assunto declaram: "A QVT baseia-se em uma visão integral das pessoas, que é o chamado enfoque biopsicossocial. O enfoque biopsicossocial das pessoas origina-se da medicina psicossomática, que propõe a visão integrada, ou holística, do ser humano" (MAXIMIANO 2000, p.498).

Segundo Albuquerque (1992), a QVT vem ganhando espaço como valor essencial das praticas de competitividade constantemente ao bem-estar organizacional enfocando o contexto, onde as organizações procuram a produtividade e processos de mudança onde para ter posicionamento competitivo no mercado precisa-se melhorar seu posicionamento.

Vasconcelos apud França (2001, pg 25) “A construção da qualidade de vida no trabalho ocorre a partir do momento em que se olha a empresa e as pessoas como um todo, o que chamamos de enfoque biopsicossocial."

A qualidade de vida no trabalho (QVT), de acordo com CHIAVENATO (1999, p.391) "representa em que graus os membros da organização são capazes de satisfazer suas necessidades pessoais através do seu trabalho na organização." Os fatores envolvidos na QVT, que são:

\begin{abstract}
A satisfação com o trabalho executado; as possibilidades de futuro na organização; o reconhecimento pelos resultados alcançados; o salário recebido; os benefícios auferidos; o relacionamento humano dentro do grupo e da organização; o ambiente psicológico e físico do trabalho; a liberdade e responsabilidade de decidir e as possibilidades de participar. CHIAVENATO (1999, pg.391)
\end{abstract}

Todo colaborador gostaria de ser reconhecido pelo seu esforço prestado, por este motivo a QVT trata de que o ser humano seja visto como uma peça essencial na organização, levando em conta os desafios do mundo atual.

\title{
Os modelos de QVT
}

Alguma dificuldade para atingir a QVT nas organizações reside na "Diversidade das preferências humanas e diferenças individuais e o grau de importância que cada trabalhador dá as suas necessidades, implicando provavelmente em denotado custo operacional“" (QUIRINO; XAVIER, 1986). 
Diversos estudiosos ao longo dos anos foram realizados para demonstrar os fatores que afetam a qualidade de vida no trabalho desenvolveram modelos de indicadores de qualidade de vida entre eles Nadler e Lawler, Walton, Hackman e Oldhan, criaram indicadores mostrando os fatores que influenciam na qualidade de vida dos indivíduos na organização.

\section{Modelo de QVT de Nadler e Lawler}

De acordo com NADLER \& LAWER apud CHIAVENATO (1999, pg.392) a QVT está fundamentada em quatro aspectos:

1- Participação dos funcionários nas decisões.

2- Reestruturação do trabalho através do enriquecimento de tarefas e de grupos autônomos de trabalho.

3- Inovação no sistema de recompensas para influenciar o clima organizacional.

4- Melhoria no ambiente de trabalho, tanto físico quanto psicológico.

Estes aspectos demonstram que o ser humano passa a ser parte integrante das organizações e mostra a evolução da importância dos mesmos. Por exemplo,: a tendência da participação nas decisões ganha espaço, ao invés da idéia predominante até pouco, que os funcionários deviam ser simples executores e outros com mais capacidades, os planejadores e "pensadores".

\section{Modelo de Hackman e Oldhan}

Segundo HACKMAN \& OLDHAN apud CHIAVENATO (1999, pg.392) "as dimensões dos cargos refletem em aspectos psicológicos que afetam os resultados pessoais e de trabalho, que interferem na QVT.” Estas dimensões do cargo são:

1- Variedade de habilidades.

2- Identidade da tarefa.

3- Significado da tarefa.

4- Autonomia. 
5- Retroação do próprio trabalho.

6- Retroação extrínseca.

7-Inter-relacionamento.

Os referidos autores "utilizam um modelo de pesquisa sobre o diagnóstico do trabalho baseado em um inventário das características do cargo para medir o grau de satisfação geral e o grau de motivação interna como diagnóstico da QVT". (CHIAVENATO, 1999, p.392)

Conforme Davis e Newstrom (1992, p.151) “as dimensões essenciais tendem a promover a motivação, a satisfação, à qualidade do trabalho e a reduzir a rotatividade e o absenteísmo.” (1992, p.151)

Os aspectos baseados nos cargos são: (CHIAVENATO, 1999, p.392)

- Variedades de habilidades: o cargo exercido deve exigir várias e diferentes habilidades e conhecimento.

- Identidade da tarefa: ressalta a importância do indivíduo sobre as suas tarefas, o trabalho deve ser realizado do início ao fim, para que este perceba que produz um resultado palpável.

- Significado da tarefa: a pessoa deve ter uma clara percepção de que forma o seu trabalho produz conseqüência e impactos sobre o trabalho dos demais.

- Autonomia: defende-se a responsabilidade pessoal para planejar e executar as tarefas e independência para desempenhá-las.

- Feedback : refere-se às informações, pode ser dividido em retroação do próprio trabalho e retroação extrínseca.

- Retroação do próprio trabalho: os superiores devem proporcionar informação de retorno para que o próprio indivíduo possa avaliar o seu desempenho.

- Retroação extrínseca: deve haver um retorno dos superiores hierárquicos ou cliente a respeito do desempenho de sua tarefa.

A idéia do feedback é de grade. Importância para os trabalhadores, já que é a forma de retorno que o indivíduo poderá fazer uma auto-envaluação, levando em conta as melhorias no âmbito laboral.

- Inter-relacionamento: o contato interpessoal do ocupante com outras pessoas ou clientes devera ser estimulado e possibilitado.

Observa-se a importância dos administradores para a conscientização da qualidade de vida dos trabalhadores. A tarefa pode ser simples, mas de vital importância para o processo e 
isso ser entendido pelo executor, o que traz um sentido de satisfação pessoal ao indivíduo no ato de desempenhar o trabalho que lhe foi designado.

\section{O modelo de Walton}

O modelo proposto por Walton, apresentado a seguir é divido em oito fatores e cada um deles abrange várias dimensões.

Líneas: Categorias conceituais de Qualidade de Vida no Trabalho (QVT)

\begin{tabular}{|c|c|}
\hline Critérios & Indicadores de QVT \\
\hline 1.- Compensação justa e adequada & $\begin{array}{l}\text { Equidade interna e externa. } \\
\text { Justiça na Compensação } \\
\text { Partilhas de ganhos de produtividade }\end{array}$ \\
\hline 2.-Condições de trabalho & $\begin{array}{l}\text { Jornada de trabalho razoável. } \\
\text { Ambiente físico seguro e saudável. } \\
\text { Ausência de insalubridade. }\end{array}$ \\
\hline 3.-Uso e desenvolvimento de capacidades & $\begin{array}{l}\text { Autonomia } \\
\text { Autocontrole } \\
\text { Qualidade múltipla } \\
\text { Informações sobre o processo total de trabalho }\end{array}$ \\
\hline 4.- Oportunidade de crescimento e segurança & $\begin{array}{l}\text { Possibilidade de carreira. } \\
\text { Crescimento pessoal. } \\
\text { Perspectivas de avanço salarial. } \\
\text { Segurança de emprego }\end{array}$ \\
\hline 5.-Integração social na organização & $\begin{array}{l}\text { Ausência de preconceitos } \\
\text { Igualdade } \\
\text { Mobilidade } \\
\text { Relacionamento } \\
\text { Senso comunicativo }\end{array}$ \\
\hline 6.-Constitucionalismo & $\begin{array}{l}\text { Direitos de proteção ao trabalhador } \\
\text { Privacidade pessoal } \\
\text { Liberdade de expressão } \\
\text { Tratamento imparcial } \\
\text { Direito trabalhistas } \\
\end{array}$ \\
\hline 7.-O trabalho e o espaço total de vida. & $\begin{array}{l}\text { Papel balanceado no trabalho } \\
\text { Estabilidade de horários } \\
\text { Poucas mudanças geográficas } \\
\text { Tempo para lazer da família }\end{array}$ \\
\hline 8.- Relevância social do trabalho na vida & $\begin{array}{l}\text { Imagem da empresa } \\
\text { Responsabilidade social na empresa } \\
\text { Responsabilidade pelos produtos } \\
\text { Praticas de emprego }\end{array}$ \\
\hline
\end{tabular}

Fonte: adaptado de CHIAVENATO (1.999, p. 393). 
Percebe-se que as dimensões da QVT são abrangentes, basicamente envolvem a vida tanto organizacional como social, o que confirma a visão biopsicossocial.

Estes fatores confirmam a importância do bem-estar dos trabalhadores para a saúde da organização. Além disso, percebe-se o papel do ser humano: cada vez mais integrante, de valor e participante na vida das organizações. Dentre estes fatores pode-se destacar:

- Utilização e desenvolvimento de capacidades: a organização passa a dar espaço para que as potencialidades do indivíduo sejam desenvolvidas e utilizadas. Esta postura, por parte da administração, é um dos novos paradigmas: antes as pessoas eram "treinadas" para trabalhos repetitivos, enquanto que hoje, a tecnologia executa estes tipos de trabalhos e as pessoas precisam desenvolver suas capacidades. A tendência é que as pessoas tenham certo grau de autonomia e identificação com o trabalho.

- Oportunidades de crescimento contínuo: o trabalho deve proporcionar crescimento e desafios constantes. As pessoas são muito mais capazes do que pensam que são, mas para isso a organização deve oportunizar o crescimento, tanto em termos pessoais e intelectuais como profissional.

- Integração social na organização: neste aspecto fica evidente a importância da igualdade de oportunidades.

- Garantias constitucionais: a liberdade de expressão e o respeito à individualidade e diferenças devem ser respeitadas pela organização.

\section{Metodologia}

Esta pesquisa visa identificar os fatores de avaliação da qualidade de vida no trabalho. Para tanto buscará identificar os setores onde a qualidade de vida no trabalho (QVT) é melhor avaliado No estudo se optou por uma pesquisa quantitativa com análises descritivas. Pesquisa quantitativa segundo Staw (1977) apud Roesh [...] “A pesquisa quantitativa é apropriada para avaliar mudanças em grandes organizações. "

Para construir o estudo se realizou uma pesquisa bibliográfica. Para Rodrigues (2007 p.43) a pesquisa bibliográfica "È a pesquisa que integra o âmbito da pesquisa ex-post-facto, pelo simples fato de que os livros e artigos de revista ou periódico qualquer tratam, via de regra, de fatos consumados." e Leite (2008 p.47) complementa "A pesquisa bibliográfica 
cujos dados e informações são coletados em obras já existentes e servem de base para análise e a interpretação dos mesmos, formando um novo trabalho cientifica."

Esta pesquisa se caracteriza como um estudo de caso. De acordo com Stake (1994) apud Roesch (2007 p.200) “O estudo de caso não é um método, mas a escolha de um objeto a ser estudado. O estudo de caso pode ser único ou múltiplo e a unidade de análise pode ser um ou mais indivíduos, grupos, organizações, eventos."

Para realizar o estudo de caso, foi preciso utilizar a pesquisa em campo, o que possibilitou este estudo como uma pesquisa empírica. A pesquisa de campo é conceituada por Lakatos (2009 p.69) da seguinte maneira: “Consiste na observação de fatos e fenômenos tal como ocorrem espontaneamente, na coleta de dados a eles referentes e no registro de variáveis que se presumem relevantes, para analisá-los".

Para Leite (2008 p.286) este tipo de pesquisa é utilizado com o objetivo de conseguir informações e/ou conhecimentos acerca de um problema para a qual se procura uma resposta ou de uma hipótese que se queira comprovar, ou ainda, descobrir novos fenômenos, ou as relações entre eles.

Para a coleta de dados será aplicados questionários estruturados. As entrevistas estruturadas são elaboradas mediante questionário totalmente estruturado, ou seja, é aquela onde as perguntas são previamente formuladas e tem-se o cuidado de não fugir a elas. $\mathrm{O}$ principal motivo deste zelo é a possibilidade de comparação com o mesmo conjunto de perguntas e que as diferenças devem refletir diferenças entre os respondentes e não diferença nas perguntas (LODI, 1974 apud LAKATOS, 1996).

O questionário é composto de perguntas relacionadas a qualidade de vida no trabalho (QVT) e perguntas sócio-econômicas.

\section{Estudo de caso}

O estudo de caso abordado nesta pesquisa realizou-se nos colégios: Nossa Senhora de Fátima e São Francisco de Assis, localizados em Barbalha e Juazeiro do Norte/CE, respectivamente, no período de 10 a 15 de Novembro de 2015. 


\section{Identificação das Empresas:}

Nome da Empresa: Colégio Nossa Senhora de Fátima

Ramo de atividade: Educação

Endereço: Av Matriz nº 258

Cidade: Barbalha -CE

Telefone:(88) 35321074

Número de Funcionários: aprox.136

Nome da Empresa: Colegio São Francisco de Assis

Ramo de atividade: Educaçao

Endereço: Rua Nossa Senhora do Carmo, s/n

Cidade:Juazeiro do Norte - CE

Telefone: (88) 35112211

Número de Funcionários: aprox 52

\section{Descrições dos negócios}

Os colégios Nossa Senhora De Fátima e São Francisco de Assis, disponibilizam serviços de educação integral particular, ambas escolas oferecem educação desde o ensino infantil ate o cientifico; ambas escolas desenvolvem projetos interdisciplinares, voltada para a construção da cidadania e do conhecimento, bem como aquisição de valores e habilidades..

\section{Análise dos Resultados}

Para analisar descritivamente os elementos se criarem alguns parâmetros: as medias entre 04 e 05 foram consideradas altas, considerando que foi bem avaliado; já as medias de 03 á 04 foram consideradas intermediarias, entendendo-se como satisfação moderada na qualidade de vida; as medias ate o 03 foram considerados baixos, isto quer dizer, que o item foi mal avaliado pelos entrevistados 
No desvio padrão os valores de Zero ate 0,8 tiveram um desvio baixo, isto significa, que as respostas foram diferentes; os valores a partir de 0,8 ate 1,2 o desvio é intermediário e nos valores acima de 1,2, o desvio considera-se elevado considerando que as perguntas foram divergentes.

\section{Análise Descritiva das variáveis}

Para analisar e fazer o levantamento do questionário, se agruparam em 8 conceitos levantados por Walton

Tabela 01. Compensação justa, adequada e condições de trabalho.

\begin{tabular}{|l|l|l|l|}
\hline \multicolumn{1}{|c|}{ Questões } & $\mathrm{N}$ & Média & \multicolumn{1}{|c|}{$\begin{array}{l}\text { Desvio } \\
\text { Padrão }\end{array}$} \\
\hline $\begin{array}{l}\text { 1. Seu salário comparado com as funções que desempenha é } \\
\text { considerado justo por você? }\end{array}$ & 60 & 2,60 & 0,49 \\
\hline $\begin{array}{l}\text { 2. Existe diferença salarial entre os servidores que ocupam a } \\
\text { mesma função? }\end{array}$ & 60 & 2,73 & 0,61 \\
\hline 3. Sua jornada de trabalho é cansativa ou estressante? & 60 & 2,20 & 0,82 \\
\hline $\begin{array}{l}\text { 4. Como você classifica as condições ambientais de trabalho } \\
\text { (iluminação higiene, ventilação e organização) na Empresa? }\end{array}$ & 60 & 3,42 & 0,56 \\
\hline
\end{tabular}

Fonte: Dados da Pesquisa 2015.

No Quadro acima as questões 1,2,3 tiveram as media(2,60) $(2,73)$ e $(2,20)$ respectivamente;considerado-se baixas ,isto quer dizer que existe uma satisfação baixa em relação ao salário ser justo nas funções que desempenham e a diferença salarial na mesma função desempenhada. 
Tabela 02. Condições de Trabalho

\begin{tabular}{|l|l|l|l|}
\hline \multicolumn{1}{|c|}{ Questões } & $\mathrm{N}$ & Média & $\begin{array}{l}\text { Desvio } \\
\text { Padrão }\end{array}$ \\
\hline $\begin{array}{l}\text { 1.-Seu tempo de trabalho é o suficiente para a } \\
\text { realização de suas tarefas? }\end{array}$ & 60 & 4,60 & 0,62 \\
\hline $\begin{array}{l}\text { 2.- Seu intervalo de almoço e lanche é suficiente para a } \\
\text { satisfação de sua necessidades e não prejudica em nada } \\
\text { seu trabalho? }\end{array}$ & 60 & 4,08 & 0,79 \\
\hline $\begin{array}{l}\text { 3.- Em seu ambiente de trabalho, o ruído, o calor, a } \\
\text { poeira prejudicam sua saúde? }\end{array}$ & 60 & 2,45 & 0,75 \\
\hline $\begin{array}{l}\text { 4.- Na empresa todos utilizam as ferramentas e técnicas } \\
\text { de proteção e segurança? }\end{array}$ & 60 & 3,68 & 0,70 \\
\hline
\end{tabular}

Fonte: Dados da pesquisa 2015.

A tabela 2 mostra que as questões 1 e 2 obtivera medias altas (4.60) e (4.08), significando que as o tempo e o intervalo são suficientes para realizar seus objetivos.A questão04 obteve uma media intermediaria (3.68), o que quer dizer que existe uma satisfação moderada no uso das ferramentas de proteção e segurança. Na questão 3 se obteve uma, media baixa (2.45), indicando que os funcionários avaliaram mal o ambiente de trabalho.

Tabela 03. Uso e desenvolvimento de capacidades.

\begin{tabular}{|l|l|l|l|}
\hline \multicolumn{1}{|c|}{ Questões } & $\mathrm{N}$ & Média & $\begin{array}{l}\text { Desvio } \\
\text { Padrão }\end{array}$ \\
\hline 1. $\begin{array}{l}\text { Você necessita receber autorização superior para } \\
\text { decidir o que fazer e como fazer o trabalho? }\end{array}$ & 60 & 2,42 & 0,56 \\
\hline $\begin{array}{l}\text { 2. É de seu conhecimento o processo completo das tarefas } \\
\text { executadas na Instituição de Ensino? }\end{array}$ & 60 & 3,83 & 0,98 \\
\hline
\end{tabular}

Fonte: Dados da pesquisa 2015.

A tabela 3 demonstra que a questão 1 obteve uma media baixa, significando a mal avaliação e insatisfação dos respondentes em relação a necessidade de receber autorização para decidir o que fazer e como fazer o seu trabalho.A questão 2 mostra uma media considerada intermediaria significando uma satisfação moderada em relação o conhecimento do processo completo das tarefas executadas na instituição de ensino. 
Tabela 04. Oportunidade de Crescimento e Segurança.

\begin{tabular}{|l|l|l|l|}
\hline \multicolumn{1}{|c|}{ Questões } & N & Média & $\begin{array}{l}\text { Desvio } \\
\text { Padrão }\end{array}$ \\
\hline $\begin{array}{l}\text { 1. Como você considera seu relacionamento com os demais } \\
\text { colegas? }\end{array}$ & 60 & 4,35 & 0,78 \\
\hline $\begin{array}{l}\text { 2. Como você considera o relacionamento existente entre } \\
\text { os superiores e os demais servidores? }\end{array}$ & 60 & 4,05 & 0,70 \\
\hline
\end{tabular}

Fonte: Dados da pesquisa 2015.

$\mathrm{Na}$ tabela 4 se obseva que a questão 1 obteve media intermediaria (3.89) , significa que a organização incentiva na continuidade dos estudos. A questão 2 obteve uma media alta (4.33), o que significa que os funcionários se sentem como peça fundamental da instituição de ensino

Tabela 05. Integração social na organização

\begin{tabular}{|l|l|l|l|}
\hline \multicolumn{1}{|c|}{ Questões } & $\mathrm{N}$ & Média & $\begin{array}{l}\text { Desvio } \\
\text { Padrão }\end{array}$ \\
\hline $\begin{array}{l}\text { 1. O Órgão incentiva o empregado para continuar seus } \\
\text { estudos? }\end{array}$ & 60 & 3,89 & 0,88 \\
\hline $\begin{array}{l}\text { 2. Você se considera u ma pessoa importante para que } \\
\text { a Instituição de Ensino atinja seus objetivos? }\end{array}$ & 60 & 4,33 & 0,51 \\
\hline
\end{tabular}

Fonte: Dados da pesquisa 2015

Nesta tabela foram questionadas as perguntas relacionadas ao critério integração sociais na organização. As medias apresentadas no que diz respeito à existência de discriminação do órgão junto aos seus empregados, relacionamento entre os colegas e o relacionamento entre os superiores e os demais servidores foram todas acima de 4, evidenciando o alto índice de satisfação dos colaboradores em relação ao critério avaliado. 
Tabela 06. Constitucionalismo

\begin{tabular}{|l|l|l|l|}
\hline \multicolumn{1}{|c|}{ Questões } & $\mathrm{N}$ & Média & $\begin{array}{l}\text { Desvio } \\
\text { Padrão }\end{array}$ \\
\hline $\begin{array}{l}\text { 1. O seu trabalho influência ou prejudica sua vida } \\
\text { familiar? }\end{array}$ & 60 & 2,63 & 0,71 \\
\hline $\begin{array}{l}\text { 2. } \\
\text { Fora de seu trabalho, você tem tempo disponível para lazer e } \\
\text { atividades sociais? }\end{array}$ & 60 & 1,75 & 0,73 \\
\hline
\end{tabular}

Fonte: Dados da pesquisa (2015)

As medias apresentadas na tabela 6 foram de (3.90) e (3.83), resultados que mostram medias intermediarias, significando satisfação moderada no tocante a livre expressão para opinar aos seus superiores, à divulgação e ao debate das normas e rotinas da instituição de ensino.

Tabela 07. O trabalho e o espaço total de vida

\begin{tabular}{|l|l|l|l|}
\hline \multicolumn{1}{|c|}{ Questões } & $\mathrm{N}$ & Média & $\begin{array}{l}\text { Desvio } \\
\text { Padrão }\end{array}$ \\
\hline $\begin{array}{l}\text { 1. Como é a imagem da Instituição de Ensino junto à } \\
\text { comunidade local? }\end{array}$ & 60 & 4,27 & 0,73 \\
\hline $\begin{array}{l}\text { 2. Como você considera o espírito de comprometimento e } \\
\text { colaboração dos Professores da Instituição de Ensino } \\
\text { junto à comunidade? }\end{array}$ & 60 & 3,47 & 1,00 \\
\hline
\end{tabular}

Fonte: Dados da pesquisa (2015)

Observando os dados das medias das questões 1 e 2 , verificou-se que elas são considerada baixa, atingindo uma satisfação baixa .os desvios das questões são 0.71 e 0.73 considerados índices baixos.

Tabela 08. Relevância social do trabalho na vida.

\begin{tabular}{|l|l|l|l|}
\hline \multicolumn{1}{|c|}{ Questões } & N & Média & \multicolumn{1}{c|}{$\begin{array}{l}\text { Desvio } \\
\text { Padrão }\end{array}$} \\
\hline $\begin{array}{l}\text { 1. Você se sente a vontade para expressar sua opinião } \\
\text { aos seus superiores? }\end{array}$ & 60 & 3,90 & 0,88 \\
\hline $\begin{array}{c}\text { 2.As normas e rotinas da Instituição de Ensino são bem divulgadas e } \\
\text { são debatidas por todos? }\end{array}$ & 60 & 3,83 & 0,98 \\
\hline
\end{tabular}

Fonte: Dados da pesquisa (2015) 
O critério relevância social do trabalho na vida questionando na questão 1 , trouxe em resultado que apresentou uma media alta, pois foi bem avaliado pelos respondentes evidenciando o alto nível de satisfação, confirmando a boa imagem das escolas avaliadas junto à comunidade social. O mesmo não aconteceu com a questão 2 que apresentou uma media considerada intermediaria significando um nível de satisfação moderado em relação ao espírito de comprometimento e colaboração dos colaboradores junto à comunidade.

\section{Conclusões}

Este estudo teve como foco analisar a qualidade de vida no trabalho, com o intuito de mostrar a importância da satisfação dos colaboradores de duas instituições de ensino no cariri. O presente estudo de caso foi realizado no colégio Nossa Senhora de Fátima e no Colégio São Francisco de Assis nas cidades de Barbalha e Juazeiro do norte respectivamente, fazendo um levantamento de dados de 60 funcionários, sendo 30 de cada escola, com a intenção de Analisar a qualidade de vida no trabalho dos colaboradores e Identificar os fatores de avaliação de qualidade de vida no trabalho. com melhor avaliação na percepção dos colaboradores das escolas.

$\mathrm{Na}$ apuração dos resultados obtidos, observa-se a superioridade das medias referentes aos critérios de integração social na organização e relevância social do trabalho na vida, relevando que não observamos nenhum tipo de discriminação das instituições junto aos funcionários e que as instituições têm uma excelente imagem no que se refere ao relacionamento com a comunidade.

O critério relevância social do trabalho na vida questionando trouxe em resultado que apresentou uma media alta, pois foi bem avaliado pelos respondentes evidenciando o alto nível de satisfação, confirmando a boa imagem das escolas avaliadas junto à comunidade social. Em relação ao espírito de comprometimento e colaboração dos colaboradores junto à comunidade apresentou uma media considerada intermediaria significando um nível de satisfação moderado.

Nas condições de Trabalho abarcaram-se os tópicos referentes ao tempo e o intervalo onde obtiveram medias alta isto demonstra que são suficientes para realizar seus objetivos. 
Quando o assunto é o uso das ferramentas de proteção e segurança a media é intermediaria, o que quer dizer que existe uma satisfação moderada. Ao falar do ambiente de trabalho. Obteve uma media baixa indicando que os funcionários avaliaram mal o ambiente no qual trabalham.

Os critérios que receberam as menores medias foram se o trabalho influencia ou prejudica sua vida familiar e fora do seu trabalho, você tem tempo disponível para lazer e atividades, caracterizando a mã avaliação e a insatisfação dos funcionários.também o assunto como estresse no trabalho, cansaço, o salário comparado com as funções que desempenha foram considerados injustos, ressaltando diferença a salarial entre os funcionários que ocupam a mesma função.

Esta apuração do resultado, em resposta à problemática que abordou a questão de Analisar a qualidade de vida no trabalho dos colaboradores e Identificar os fatores de avaliação de qualidade de vida no trabalho com melhor avaliação na percepção dos colaboradores das escolas, mostrou com clareza que o órgão deve melhorar o espaço físico da organização assim como também melhorar a qualidade de vida dos seus colaboradores no sentido de fornecer informações mais necessárias sobre o processo total das tarefas, objetivando a satisfação por parte dos servidores ao desempenharem suas funções.

Os resultados obtidos nos revelam de forma clara que todos os objetivos gerais e específicos foram alcançados.

Acredita-se que essa pesquisa possa subsidiar a identificação e implementação de novas estratégias que contribuam para a melhora da qualidade de vida dos colaboradores, bem como para que os diretores e coordenadores percebam a necessidade de avaliar a qualidade de vida das pessoas, partindo da premissa de que quem sabe onde sua vida foi alterada é o próprio indivíduo.

Fica clara a necessidade de novas pesquisas com o intuito de intensificar os estudos para importância da qualidade de vida no trabalho .

\section{Referências}

BOM SUCESSO, E. P. Trabalho e Qualidade de Vida. Rio de Janeiro: Qualitymark / Dunya, 1997. 
CARVALHO, Maria do Socorro M. V; TONET, Helena C, Qualidade na administração Publica. Rio de Janeiro, 1994, v.28, n. 2, Abr./Jun.

CASTRO A. P. Qualidade de energização do patrimônio humano. Rio de Janeiro: Qualitymark, 1993.

CHIAVENATO, I. -_Gestão de Pessoas; o novo papel dos recursos humanos nas organizações. Rio de Janeiro: Campus, 1999.

CHIAVENATO, I. Introdução à teoria geral da administração. 6. Ed. rev. e atual. Rio de Janeiro: Campus, 2000.

CHIAVENATO, Idalberto. Comportamento organizacional: A dinâmica do sucesso das organizações. 2. Ed. Rio de Janeiro: Elsevier, 2005

COCCO, M. I. M. - Promoção à saúde no trabalho. Projeto de Pesquisa. Campinas, 2001.

FERNANDES, Eda Conte. Qualidade de vida no trabalho: como medir para melhorar. 2. Ed. Salvador/BA: Casa da Qualidade, 1996. 115p.

FERREIRA, Aurélio Buarque de Holanda. Novo dicionário da língua portuguesa. Rio de Janeiro: Nova Fronteira. 1986.

FRANÇA, A. C. L. Indicadores Empresariais de Qualidade de Vida: esforço empresarial e Satisfação dos empregados no ambiente de manufaturas com certificação ISO 9000. Tese de Doutorado, São Paolo: FEA/USP, 1996.

FREITAS, Maria E, Cultura organizacional: formação, tipologias e impactos, São Paulo; Makron McGraw-Hill, 1991.

LACAZ, F. A. C. - Qualidade de vida no trabalho e saúde / doença. Ciência \& Saúde Coletiva - n. 05, vol. 01, 2000.

LAKATOS, Eva Maria. Técnicas de Pesquisa. 7. Ed. São Paulo: Atlas, 2009.

LEITE, Francisco Tarcisio. Metodologia Cientifica: Métodos e Técnicas de Pesquisa: monografias, dissertações, teses e livros. Aparecida, SP: Idéias \&Letras, 2008.

LUZ, Ricardo. Clima organizacional. Rio de Janeiro: Qualitymark, 1995.

LUZ, Ricardo. Gestão do clima Organizacional. Rio de Janeiro: Qualitymark, 2003.

MAXIMIANO, Antonio César Amaru. Teoria geral da administração: da escola científica à competitividade na economia globalizada. 2. Ed. São Paulo: Atlas S.A, 2000. 530p.

MINAYO, M. S. C.; HARTZ, Z. M. A.; BUSS, P. M. - Qualidade de vida e saúde: um debate necessário. Ciência \& Saúde Coletiva - n. 05, vol. 01, 2000. 
OLIVEIRA, Marco Antonio G, Como entender a cultura organizacional, São Paulo: Nobel, 1988.

QUEIROZ, S. H. Motivação dos Quadros Operacional para a Qualidade Sob o Enfoque da Liderança Situacional. Florianópolis. UFSC, 1996.

ROBBINS, P. Comportamento organizacional. 11ed. São Paulo: Pearson Prendesse Hall, 2005.

ROBBINS, S. P. (1999). Comportamento Organizacional ( $8^{\text {a }}$ ed.). Rio de Janeiro: Livros Técnicos e Científicos.

RODRIGUES, Marcus Vinicius Carvalho. Qualidade de Vida no Trabalho: Evolução e analise no nível gerencial. Fortaleza: UNIFOR, 1991.

RODRIGUES, Martinho Rui. Pesquisa Acadêmica. São Paulo: Atlas, 2007.

ROESCH, Silva Maria Azevedo. Projetos de estagio de pesquisa em administração. 3.Ed. São Paulo : Atlas , 2007.

SIQUIERA, M. M.M. Medidas do comportamento Organizacional. Estudos de Psicologia, V7, no. Spe, Natal, 2002, p.11-18.

SOARES, Vanessa Pires. A cultura organizacional e seus componentes. Disponível em: <http://www.nead.unama.br/charles/cultura.htm>. Acesso em: 29 abr. 2002.

TACHIZAWA, Takeshy, FERREIRA, Victor Claudio Paradela, FORTUNA, Antonio Alfredo Mello. Gestão com pessoas: uma abordagem aplicada de negócios. $3^{\circ} \mathrm{ed}$. Rio de Janeiro: FGV, 2004.

TANIGUCHI. K; COSTA. A.L, Clima Organizacional: uma ferramenta estratégica o diagnostico em recursos humano Revista de Ciências Gerenciais. vol. XIII. São Paolo: Anhanguera Educacional S.A, 2010.

Como citar este artigo (Formato ABNT):

TAVARES, Marysângla de O.; LIMACHI, Islly G. T. Avaliação da Qualidade de Vida no Trabalho: Estudo de Caso em duas Escolas Particulares no Cariri Cearense. Id on Line Revista Multidisciplinar e de Psicologia, 2017, vol.11, n.38, p.127-149. ISSN: 1981-1179.

Recebido: 22.08 .2017

Aceito: 23.08 .2017 